\title{
DELEUZE E A LÓGICA DO SENTIDO: O PROBLEMA DA ESTRUTURA
}

Alessandro Carvalho SALES ${ }^{1}$

- RESUMO: Este texto pretende acompanhar os principais movimentos apresentados pelo filósofo Gilles Deleuze para propor uma estrutura do sentido, de acordo com a Lógica do sentido (1969). Para tanto, tentando nos alçar ao estruturalismo muito particular de Deleuze, seguiremos especialmente alguns argumentos estabelecidos entre a quarta (Das dualidades) e a oitava (Da estrutura) séries desse livro, bem como pontos do artigo Em que se pode reconhecer o estruturalismo? (1972).

- PALAVRAS-CHAVE: Deleuze; lógica do sentido; Estrutura; Paradoxo; Lewis Carroll.

\section{Introdução: Deleuze estruturalista?}

Nas três primeiras séries da Lógica do sentido (Do puro devir, Dos efeitos de superfície e Da proposição), de acordo com aspectos privilegiados por Deleuze especialmente quanto ao pensamento estóico, ele busca apresentar uma primeira abordagem da questão que dá título ao livro. Tratar-seia de uma espécie de fenomenologia do sentido-acontecimento: acontecimento aos corpos que se manifesta na linguagem, até o ponto extremo e visível de suas efetuações empíricas. A partir da quarta série (Das dualidades) e pelo menos até a oitava (Da estrutura), o autor vai estabelecendo a inflexão metodológica e conceitual com a qual passa a se compor, esten-

1 Doutorando no Programa de Pós-Graduação em Filosofia da Universidade Federal de São CarlosUFSCar sob orientação de Bento Prado Junior e com auxílio da Fapesp. Artigo recebido em jan/06 e aprovado para publicação em nov/06. 
dendo o novo âmbito segundo o qual a questão se coloca e seguindo no embate teórico que tenta dar conta da problemática do sentido. Quanto a este ponto, eis o que nos coloca François Wahl:

O sentido foi considerado até aqui por Deleuze em sua relação com aquilo sem o qual ele não é (...) mas aquém do qual - um aquém transcendental - seu ser, ou 'extra-ser' - se afirma. É preciso chegar às relações internas ao sentido. (Wahl, 2000, p.131)

Nesta citação, 'transcendental' não se refere ao uso kantiano do termo. Deleuze reconhece a Kant a relevância da descoberta de tal conceito, ${ }^{2}$ mas, na crítica que leva a efeito, termina por deslocar o seu sentido. Em Kant, "(...) é transcendental, por oposição ao empírico, aquilo que é uma condição a priori e não um dado da experiência (...) Por conseqüência, diz-se transcendental todo estudo que tem como objeto as formas, princípios ou idéias a priori na sua relação necessária com a experiência" (Lalande, 1999, p.1151). Kant estabelece o estatuto do transcendental como constitutivo da experiência, como o conhecimento das condições apriorísticas de toda experiência possível. Porém, de acordo com nosso autor, ele ainda "(..) decalca as estruturas ditas transcendentais sobre os atos empíricos de uma consciência psicológica: a síntese transcendental da apreensão é diretamente induzida de uma apreensão empírica etc" (Deleuze, 1988, p.224). O transcendental kantiano seria estabelecido relativamente à forma pura do objeto e à forma pura da consciência, o que não os desligaria do plano empírico.

Sabemos que Deleuze, ao distinguir o sentido da significação, tenciona investigar as condições efetivas de uma gênese intrínseca ao sentido. Kant permaneceria vinculado a um tipo de condicionamento extrínseco, justamente aquele que ainda projeta a condição como imagem, possibilidade do condicionado, de modo semelhante ao que se passa com a significação. Deleuze (idem, p.252) espera, com o seu empreendimento, escapar da experiência previsível do possível, para se alçar à experiência real.

Ao não se contentar com as conformações empíricas, fenomenológicas, dos seus objetos de estudo, ele busca avançar ao lugar mesmo em que sequer há sujeito e objeto formados e atingir o âmbito de uma ontologia. Não basta que atinemos com as efetuações empíricas e atuais concernentes ao sentido como acontecimento. É preciso ir mais longe, correr todos os riscos e adentrar o domínio estritamente ontológico em questão: o que é o sentido enquanto acontecimento? O que o constitui? De maneira ainda mais explícita: de que ele é feito?

2 Uma citação já bem conhecida: "de todos os filósofos, Kant foi o que descobriu o prodigioso domínio do transcendental” (Deleuze, 1988, p.224) 
Vamos variar um pouco e afirmar que Deleuze não se satisfaz com o plano formal das coisas; ao contrário, as formas se dão como um produto, como efeitos de um jogo muito mais complexo e poderoso que lhes é subjacente. Este é o jogo múltiplo e enredado das potências, das forças, e constitui sua face propriamente transcendental. Podemos, ainda que muito incipientemente, inferir que o roteiro de Deleuze pretende seguir e descrever um duplo trajeto de pensamento: das formas às forças; e, logo após, o retorno à superfície. ${ }^{3}$

O deslocamento entre as duas dimensões ocorre necessariamente por disjunção, por divergência: o transcendental não pode se assemelhar ao empírico, senão retornaríamos ao contexto redundante da experiência possível. Portanto, ainda que sumariamente, diremos que sair do plano dos entes, do vivido, e mergulhar na direção do transcendental, é dissolvê-lo no denso e múltiplo conjunto de forças a partir do qual ele emerge, e de modo que o retorno só pode ser feito em nova estrada: reencontrar o ponto de partida é, em suma, não mais encontrá-lo, mas encontrar um outro, pois que modificado, transformado pelas novidades e aspectos que há pouco vieram à tona.

Na primeira etapa desse trajeto, no que toca ao problema do sentido, será preciso portanto valorizar o fato de que suas efetuações empíricas, suas relações externas - seja do lado do estado de coisas, seja do lado da linguagem -, são apenas uma face da questão, e certamente não a mais rica. Deleuze quer buscar e problematizar o outro da matéria, o seu diferente, ou, numa acepção mais peculiar do termo e como disse François Wahl, seu aquém transcendental, aquilo que lhe constitui as relações internas.

Na direção apontada, o primeiro expediente filosófico com o qual o autor vai se compor é o conceito de estrutura. Não à toa, ele afirma que "o estruturalismo não é separável de uma filosofia transcendental nova" (Deleuze, 1974, p.277). Mas - imprescindível anotá-lo -, o estruturalismo a que Deleuze vai se referir é uma certa leitura, ou, dito melhor, a sua leitura do estruturalismo, termo que designa um certo momento e uma certa instância do pensamento francês, mais exatamente aquele que se situou ao longo das décadas de 50 e 60 (especialmente), e que se estabeleceu como contraponto aos humanismos e aos psicologismos em geral, às filosofias do sujeito e da consciência, valorizando um certo caráter científico, a distinção mais evidente a ser possivelmente conferida aos saberes.

Não há dúvidas de que a paisagem do pensamento de Deleuze varia ao longo de sua produção, se agita e se modifica consideravelmente. De todo

3 Cf. Badiou, 1997, pp.48-49 e 52-54. Este autor tece críticas a Deleuze que não chegaremos a considerar. O fato, em nossa perspectiva, é que seu estudo não deixa de iluminar o sentido mais amplo de algumas das proposições deleuzeanas. 
modo, haveria aí um fundo essencial ${ }^{4}$ que, àquela época, travou relações com um certo espírito estruturalista, e cujos ecos são verificáveis, por exemplo, em Lógica do sentido e em Diferença e repetição. Há ainda um artigo fundamental, chamado Em que se pode reconhecer o estruturalismo?, ${ }^{5}$ que, ao buscar encaminhamentos para a questão apresentada e efetuar um exame de caracteres possivelmente comuns a autores tidos como estruturalistas, termina por constituir-lhes uma vestimenta que inevitavelmente faz ressoar o próprio filosofar do nosso autor, como de resto ocorre em praticamente todos os seus ensaios de história da filosofia.

Deleuze estruturalista? Examinar detidamente esta pergunta já seria, por si só, assunto para uma longa pesquisa, pois, como sabemos, não só os estruturalismos - no plural - foram variados, como também seria preciso distinguir a delicadeza e o lugar do corte específico capaz de traduzir a passagem para o chamado pós-estruturalismo. Podemos, no entanto, desde já considerar o seguinte comentário:

A estrutura, pois, tal como a entende Deleuze, nada tem a ver com uma forma fixa ou uma essência eternitária (por isso não é abstrata) (...) a leitura mais atenta deixa claro que a noção de estrutura que Deleuze enuncia aí [no texto Em que se pode reconhecer o estruturalismo?] é muito pouco estruturalista e que alguns anos antes [em relação à sua data de publicação] Diferença e repetição já enunciava praticamente as mesmíssimas características como sendo constituintes da Idéia. (Pelbart, 1998, pp.42-3)

Nossa hipótese é de que, no artigo em foco, Deleuze simplesmente dá seguimento ao seu projeto filosófico: mais do que um pensamento propriamente estruturalista, o que dele não deixa de emergir é a especificidade das suas propostas, o que enfatiza, mais uma vez, a enorme facilidade com que se apropria de idéias em curso, e, transmutando-lhes o feitio, termina por desnortear leitores e estudiosos. Assim, Deleuze foi estruturalista somente na medida em que, valendo-se de aspectos de um certo éter de idéias e de conceitos - no caso, este que ficou designado como estruturalista -, pôde,

4 Cf. Machado, 1990, p.161: "Sem dúvida alguns conceitos, e sobretudo a terminologia, têm variado durante todos esses anos de atividade filosófica. As modificações, no entanto, são secundárias para quem pretende compreender sua démarche filosófica em toda sua amplitude. O essencial do projeto de crítica da filosofia da representação (...) e o modo como Deleuze o realiza (...) permaneceram praticamente invariáveis".

5 No início deste texto, Deleuze afirma e grifa: "Estamos em 1967" (edição brasileira de 1974, p.271). É provável portanto que ele tenha sido escrito mais ou menos na mesma época em que o autor trabalhava em Diferença e Repetição e na Lógica do Sentido, publicados um pouco depois. No entanto, tal artigo só foi divulgado em 1972 (original francês), na História da Filosofia de François Châtelet. 
sutilmente diferenciando essa via, dar vazão à sua filosofia. O camaleão Deleuze, se já tinha sido humeano, nietzscheano, bergsoniano, ou mesmo kantiano, pôde então ser estruturalista. Nada mais deleuzeano, portanto.

Assim, o autor parte em busca da "estrutura objetiva do próprio acontecimento" (Deleuze, 1998, p.3). Ao longo das páginas deste texto, propomo-nos então estabelecer uma análise desta ontologia, que é também a do sentido. Em busca de sua estrutura, vamos urdir, em especial, uma costura entre pontos do escrito Em que se pode reconhecer o estruturalismo? e trechos da Lógica do sentido. Aqui, este caminho é o que começa a se desdobrar já na quarta série, Das dualidades, até aproximadamente a oitava série, Da estrutura.

\section{Dualidades}

A quarta série trata de dualidades. Porém, numa operação típica da filosofia de Deleuze, elas serão apresentadas tendo em vista precisamente a sua superação, o seu ultrapassamento. Os dualismos serão "esticados" ao ponto mesmo de sua dissolução, firmada segundo o lugar especial capaz de originá-los.

Há, de acordo com a teoria estóica do acontecimento retomada por Deleuze, uma dualidade de partida, a mais profunda, a mais exterior, que examinaremos melhor: de um lado, as misturas e as causas sensíveis, evidência corporal, e, de outro, os acontecimentos-efeitos resultantes. Porém, sabemos que os acontecimentos nos chegam na proporção em que são ditos por proposições: o liame primeiro se prolongou, se elevou à superfície, agora como o elo corpo-linguagem, a evidência linguageira, o sentido tornado possível (idem, p.25). Deleuze coloca então o problema de outro modo, sob uma ótica carrolliana do comer-falar: "Comer, ser comido, é o modelo de operação dos corpos, o tipo de sua mistura em profundidade, sua ação e paixão, seu modo de coexistência um no outro. Mas falar é o movimento da superfície, dos atributos ideais ou dos acontecimentos incorporais" (idem, p.25).

Mas reconhecemos que não pode haver uma pura demarcação entre corpo e linguagem, entre o comer e o falar. Se há códigos culturais morais que querem separar veementemente as duas ações, ${ }^{6}$ Alice, em sua procura pela superfície, não tem qualquer preocupação em relacioná-las, e não se incomoda, por exemplo, em falar de comida ou em comer palavras (idem, p.25). No caminho para um terceiro, Alan Badiou confirma os seguintes caracteres da filosofia de Deleuze:

6 Por exemplo, o fato de que não se pode falar de boca cheia, ou de que não devemos, no discurso, engolir as palavras. 
Como todo grande filósofo, ele só monta a maquinaria das oposições categoriais para determinar o ponto que se subtrai a ela, a linha de fuga que absorve suas extremidades aparentes. Esse é o sentido profundo de uma máxima metódica sobre a qual ele não deixa de insistir: tomar as coisas pelo meio; não tentar achar primeiro uma das pontas, para depois ir até a outra. (Badiou, 2000, p.159) ${ }^{7}$

O terceiro tão especial, o entre ou o meio que rasga e complica os extremos formais, será aqui caracterizado como a superfície fronteiriça a ser conquistada, a superfície que guarda os devires que se desprenderam do fundo absoluto dos corpos e que estão por se metamorfosear em acontecimento às coisas, aos objetos, e sentido na linguagem, sentido para um sujeito. Tal fronteira - a se efetuar, insistimos, segundo a confecção de proposições subjetivas e a clarificação das coisas que ocorrem - é o sentidoacontecimento, que, se chega a delimitar as duas instâncias, o faz segundo a articulação de suas diferenças. Mais que delimitá-las, separá-las, ele as conecta pela diferença. ${ }^{8}$

Assim, por meio da fronteira, a dualidade naturalmente se estende e se dissemina em cada um dos ramos: o corpo está na linguagem, a linguagem está nos corpos. No tocante às coisas, há certamente uma física, o real que lhes constitui, mas há também o atributo lógico que caracteriza o instante infinitivo de uma transformação incorporal. Já quanto às proposições, os substantivos e os adjetivos designam as coisas, mas temos também os verbos, que expressam os acontecimentos (Deleuze, 1998, p.26).

Fiquemos deste lado, do lado da proposição. Temos então nomes, estes que fixam e assinalam as coisas, segundo limites, pausas, presenças, e temos os verbos, eles que exprimem e trazem consigo os devires, as mudanças, as novidades incorporais. Deleuze aponta aí a dualidade fatal na qual queria chegar: não propriamente entre nomes e verbos, mas entre designações (de coisas) e expressões (de sentido). Ele afirma:

É como se fossem dois lados de um espelho: mas o que se acha de um lado não se parece com o que se acha do outro (...) Passar do outro lado do espelho é passar da relação de designação à relação de expressão - sem se deter nos intermediários, manifestação, significação. É chegar a uma dimensão em que a linguagem não tem mais relação com designados, mas somente com expressos, isto é, com o sentido.

7 Sugerimos também a leitura do apêndice da Lógica do sentido (1998) intitulado Klossovski ou Os Corpos-Linguagem.

8 Nas palavras de Deleuze (1998, p.26): "As coisas e as proposições acham-se menos em uma dualidade radical do que de um lado e de outro de uma fronteira representada pelo sentido. Esta fronteira não os mistura, não os reúne (não há monismo tanto quanto não há dualismo), ela é, antes, a articulação de sua diferença: corpo/linguagem". O mirante de Deleuze tornar-se-á cada vez mais claro: sua fronteira não será aquilo que irá delimitar, restringir, mas o que vai poder relacionar e articular os diferentes 
Tal é o último deslocamento da dualidade: ela passa agora para o interior da proposição. (idem, p.27)

Atingimos um lugar central. Deleuze parte da relação profunda misturas corporais-acontecimentos incorporais. Tal relação, emergindo à superfície, se dá entre corpo e linguagem. Na face da linguagem, da proposição, a dualidade é entre nomes e verbos, ou melhor, entre designações e expressões. "É a mesma dualidade (...) que passa pelo lado de fora entre os acontecimentos e os estados de coisas, na superfície entre as proposições e os objetos designados e no interior da proposição entre as expressões e as designações" (idem, p.40). No entanto, ao tender para a linguagem, linguagem que inevitavelmente carrega um devir-corpo, o autor chega ao par designação-expressão, que servirá, como veremos, de fulcro para uma teoria das séries, caminho para a estrutura. De outro modo, diremos que Deleuze, partindo da acontecimentalização profunda dos corpos, buscou chegar no nível específico da linguagem de superfície, que passará a pensar segundo uma teoria das séries, ou melhor, segundo sua estrutura, desde que em tal linguagem se evidencie a distinção entre designações e expressões.

Veremos Deleuze caracterizar a distinção em foco a partir de um trecho de Alice no país das maravilhas. O fragmento é parte do terceiro capítulo, Uma corrida em comitê e uma história comprida, quando, às margens da lagoa de lágrimas, ela se encontra com um estranho grupo de animais, e todos se reúnem para ouvir o camudongo. A certa altura, o papagaio parece incomodado:

"Arre!" soltou o Papagaio, com um arrepio.

"Perdão!"falou o Camudongo, fechando a cara, mas muito polido: "Disse alguma coisa?"

"Eu não!" o Papagaio se apressou em responder.

"Pensei que tinha", disse o Camudongo. "Continuando: 'Edwin e Morcar, condes da Mércia e da Nortúmbria, proclamaram seu apoio a ele e até Stigand, o patriótico arcebispo de Canterbury, achando isso oportuno..."

"Achando o quê?" indagou o Pato.

"Achando isso", respondeu o Camudongo, bastante irritado. "Suponho que saiba o que 'isso' significa."

"Sei muito bem o que 'isso' significa quando eu acho uma coisa", disse o Pato. "Em geral é uma rã ou uma minhoca. A questão é: o que foi que o arcebispo achou?" Sem tomar conhecimento da pergunta, o Camudongo se apreesou em continuar: "achando isso oportuno, foi com Edgar Atheling ao encontro de Guilherme e lhe ofereceu a coroa". (Carrol, 2002, p.28)

9 Atentemos para o espelho apresentado: ele não é nada perfeito, um espelho idealizado de pura semelhança; pelo contrário, a reflexão, no caso, é o que se dá pela diferença, pela dessemelhança.

10 Nas Aventuras de Alice (Carroll, 1980), p.54, na Lógica do sentido (Deleuze, 1998), a história é relatada na p.27. 
A questão que se interpõe entre o pato e o rato, segundo Deleuze, é a distância entre a designação e a expressão. Enquanto o primeiro compreende o isso como pura instância de determinação, indicadora de coisas e estados de coisas, o segundo toma a partícula como o expresso, o sentido de uma outra proposição (qual seja, ir ao encontro de Guilherme para oferecerlhe a coroa). (Deleuze, 1998, p.27) Comenta Deleuze:

As duas dimensões da proposição se organizam em duas séries que não convergem senão no infinito, em um termo tão ambíguo quanto isto, uma vez que se encontram somente na fronteira que não cessam de bordejar. E uma das séries retoma à sua maneira "comer", enquanto que a outra extrai a essência de "falar". (idem, p.27-8)

Sem dúvida a poesia e a literatura modernas conhecem muito de perto este tipo de construção, que se dá, por exemplo (e no caso acima), na medida em que uma única palavra é capaz de desencadear a existência de duas séries diversas, heterogêneas, tais que uma é mais afim a uma condição objetiva de designação, de indicação, ao passo que a outra diz respeito aos acontecimentos, aos sentidos expressos. Estas dimensões estão aí conectadas por uma palavra muito especial, chamada esotérica, "fronteira perpetuamente contornada, ao mesmo tempo que traçada pelas duas séries" (idem, p.28).

Vemos a antinomia instaurada por uma palavra desta estirpe. Ela nos convida a dois caminhos de sentido que, por um lado, são diversos: um deles é perfeitamente objetivo e literal, o outro, muito mais simbólico, expressivo (idem, p.28). De outro lado, porém, o sentido não diz respeito a apenas uma das duas vias. Ele não vem se instalar segundo uma pura escolha, um ou exclusivo. ${ }^{11}$ Pelo contrário, ele pode ser as duas, ele é uma e outra, a fronteira que as encaixa pela diferença, e que não pode deixar, assim, de ser paradoxal. Como se, por um caminho, dispuséssemos de um sentido mais "duro", estrito, ao passo que o outro nos levaria a um sentido mais "mole", maleável; no entanto, surpreendentemente descobrimos que ambos estão vinculados, há uma estrada, uma densa linha que os liga, segundo a palavra-fronteira que os institui.

\section{Paradoxos}

Se o sentido tem pois este caráter disparatado, seguiremos Deleuze e tentaremos apresentar, ainda que um pouco brevemente, os quatro parado-

11 O ou exclusivo é a operação lógica cuja tabela de verdade é verdadeira sempre que um - e apenas um - dos dois operandos é verdadeiro. É muito próximo da linguagem cotidiana: "ou isto ou aquilo"; ou seja, um dos dois, mas não ambos. 
xos principais relacionados à sua constituição interna; é que em si mesmo o sentido é paradoxal. O primeiro deles é o paradoxo da regressão ou da proliferação indefinida. O autor lembra, com Bergson, que a condição primeira para os enunciados é o sentido. Nosso ponto de partida é o sentido: de dentro dele é que atualizamos enunciados, ele é a condição para a proposição e de modo que, assim, um eu se habilita a falar (idem, p.31). Há uma conseqüência: "Nunca digo o sentido daquilo que digo. Mas, em compensação, posso sempre tomar o sentido do que digo como objeto de uma outra proposição, da qual, por sua vez, não digo o sentido" (ibidem). Para falar o sentido de uma palavra a, não temos saída senão usar outra palavra b. Porém, para explicar o sentido da palavra b, precisamos dispor de uma outra palavra c, e assim numa regressão indefinida.

Não falamos sentidos, mas proposições, enunciados. De cada enunciado falado, depreende-se uma espécie de nuvem de sentido que condiciona um novo enunciado e assim por diante. Uma proposição nunca fecha um sentido, nunca dá conta dele por completo: sempre haverá um resto, um segredo, uma inexatidão a partir da qual poderemos fazer derivar uma outra proposição. De fato, se tivéssemos uma função absoluta, uma inequívoca correspondência entre proposição e sentido, os dicionários seriam obras perfeitas e acabadas, a linguagem perderia todo o seu dinamismo e, pior, perderia seus poetas.

Esta regressão dá testemunho, ao mesmo tempo, da maior impotência daquele que fala e da mais alta potência da linguagem: minha impotência em dizer o sentido do que digo, em dizer ao mesmo tempo alguma coisa e seu sentido, mas também o poder infinito da linguagem de falar sobre as palavras. (ibidem)

Dada então uma proposição designando uma coisa ou estado de coisas, tentar tomar seu sentido implicará compor uma segunda proposição, cujo sentido, por sua vez, será o objeto de uma terceira... "Para cada um de seus nomes, a linguagem deve conter um nome para o sentido deste nome" (idem, p.32). É o paradoxo de Frege, capaz de gerar uma derivação infinita a partir de dois termos que se alternam, quais sejam, um nome e um nomesentido deste nome. ${ }^{12}$

12 Para Deleuze (1998), é também o paradoxo de Carroll: "Ele aparece rigorosamente do outro lado do espelho, no encontro de Alice com o cavaleiro" (p.32). Cf. este exemplo particular nas Aventuras de Alice (Carroll, 1980), pp.221-222, ou, na Alice: Edição Comentada (Carroll, 2002), pp.234-235. Dias faz aí um comentário bastante incisivo: “(...) é o paradoxo de Frege, o paradoxo da ilimitada regressão do sentido, que só prova a inaptidão da lógica para atingir o plano virtual, não referencial, do sentido, ou a ilegitimidade da pretensão lógica de proposicionalizar o conceito filosófico como cristalização do sentido-acontecimento" (Dias, 1995, p.98). 
O segundo paradoxo é o do desdobramento estéril ou da reiteração seca (idem, p.34). Há que se estancar a cadeia acima descrita em alguma etapa: neste ponto singular, o sentido é propriamente depreendido da proposição, sorriso sem gato, chama sem vela. Situamos então o sentido como o duplo enevoado procedente de um enunciado, mas dele totalmente independente, e, como tal, estabelecido acima de qualquer valor lógico proposicional (o sentido não afirma nem nega, não é verdadeiro nem falso), bem como estéril, impassível (nem ativo nem passivo). Com efeito, lembrando que o sentido-acontecimento é sempre extra-ser e extra-proposicional, este paradoxo quer afirmar especificamente seu caráter de indiferença, nem agente nem paciente, frente aos estados de coisas, diversamente deles. " $\mathrm{E}$ era um dos pontos mais notáveis da lógica estóica esta esterilidade do sentido-acontecimento: somente os corpos agem e padecem, mas não os incorporais, que resultam das ações e das paixões. Este paradoxo podemos, pois, chamá-lo de paradoxo dos estóicos" (idem, p.34). Diz respeito ainda à chamada impenetrabilidade, que Deleuze tanto valoriza com Humpty Dumpty e Lewis Carroll (idem, pp.26-7). ${ }^{13}$

Por sua vez, o paradoxo da neutralidade ou do terceiro-estado da essência decorre da consideração anterior, pois, na medida em que o duplo transcendental liberado da proposição, estéril e sem valor lógico atribuível, é indiferente aos estados de coisas, ele deve também ser indiferente aos quatro modos da proposição (idem, p.35). ${ }^{14}$ Em outras palavras, o sentido deve permanecer o mesmo para proposições que se distinguem e se opõem em termos de qualidade, quantidade, relação e modalidade.

A evidência maior é que os modos da proposição, tema estudado desde os trabalhos de Aristóteles, dizem respeito a uma série de relações que podem ser estabelecidas entre proposições, sempre em função dos valores lógicos que podemos lhes atribuir, verdade ou falsidade, de acordo com a correspondência - ou não - a um certo estado de coisas. Tais modos se fundam nesta possibilidade consoante quatro aspectos distintos. No entanto, podemos já notar: a condição de verdade é o que nos tolhe, como vimos no item anterior, dentro do círculo tautológico da proposição. O sentido é justamente o plano transcendental que antecede e sustenta as efetuações empíricas relativas ao círculo e de modo algum é por elas afetado.

Assim, as proposições podem ser classificadas segundo a qualidade (afirmativas e negativas: "Deus é" e "Deus não é"); a quantidade (universal

13 Eis então que há uma sinonímia entre impassibilidade, esterilidade, secura, tudo concernente à indiferença do sentido frente aos estados de coisas.

14 No tocante especificamente aos modos da proposição - qualidade, quantidade, relação e modalidade -, sugerimos, por exemplo, Chauí, 2002 , pp.363-367, e Copi, 1978, pp.143-146. 
e particular: "todos os homens são brancos" e "alguns homens são brancos", "nenhuma caneta é vermelha" e "algumas canetas não são vermelhas"); a relação (Deleuze fala das proposições que guardam algum tipo de "relação invertida" $)^{15}$ e a modalidade (em que ele remete diretamente às proposições necessárias ou possíveis em função do tempo cronológico) (idem, p.35-7). ${ }^{16}$ Porém, no tocante ao sentido, estas tipificações se dissipam, "pois todos estes pontos de vista concernem à designação e aos diversos aspectos de sua efetuação ou preenchimento por estados de coisas e não ao sentido ou à expressão" (idem, p.35)

Deleuze chega a retomar um filósofo árabe medieval, Avicena, que discernia três estados da essência (idem, p.37). Quando as essências estão encarnadas nas coisas, elas são chamadas de singulares ou físicas. O intelecto, ao entrar em contato com as coisas, lhes apreende as essências, mas sob a forma do universal, sob a forma do conceito. Por exemplo, o intelecto, a razão, não apreende a singularidade de uma cadeira, mas ele asbtrai a sua generalidade, o seu conceito, isto é, a cadeira. Assim, no intelecto, as essências singulares das coisas passam a ser universais; também não são mais físicas, mas lógicas. No entanto, Avicena, em pleno século XI, propôs um terceiro estado da essência, além da essência universal ou lógica e da singular ou física. Tratar-se-ia da essência em si mesma, metafísica (idem,

15 Aqui, faremos duas observações. Primeiramente, sugerimos verificar o chamado quadrado dos opostos, figura criada pelos medievais a partir da lógica aristotélica. Cf., por exemplo, Chaú, 2002, p.366, ou Copi 1978, p.148. Tal figura apresenta as chamadas relações de contradição, contrariedade, subcontrariedade e subalternação entre os valores lógicos de proposições de mesmo sujeito e mesmo predicado, mas com qualidades e quantidades diferentes; seguramente podemos ligá-las ao que Deleuze chama de "relação invertida". Acreditamos que, para o autor, a relevância do quadrado dos opostos dar-se-ia no plano das significações e das designações, dos valores lógicos plenamente determináveis, mas não relativamente aos sentidos. Uma segunda observação se refere às proposições em que há permuta entre sujeito e predicado, de acordo com os exemplos que Deleuze tira de Carroll, "onde vemos que 'os gatos comem os morcegos' e 'os morcegos comem os gatos', digo o que penso' e 'penso o que digo' (...)" (Deleuze, 1998, p.36). É que o sentido transcendental é sempre duplo sentido e foge a qualquer relação causal (pois, sabemos, os acontecimentos, como incorporais, são sempre efeitos, mas nunca causas, sempre inativos); deste modo, tais enunciados, independentemente da inversão entre sujeito e predicado, se reservariam o mesmo sentido.

16 O amanhã, o futuro, está no campo do possível; o ontem, o passado, no campo do necessário. O que é possível pode se tornar necessário. Quando enuncio que "amanhã, choverá", é possível que amanhã caia uma chuva. Chegado o amanhã, e tendo chovido, o que era um futuro possível tornou-se um passado necessário. Como diz Deleuze (1998, p.36): "E se o acontecimento é possível no futuro e real [ou necessário] no passado, é preciso que seja os dois ao mesmo tempo, pois ele então se divide aí ao mesmo tempo (...) É próprio também do acontecimento ser dito como futuro pela proposição, mas não é menos próprio à proposição dizer o acontecimento como passado". A subjetividade é refém da sucessão temporal, da possibilidade e da necessidade; mas não o sentido-acontecimento que se dá numa outra dimensão, e que é sempre os dois simultaneamente; ou, como diz o autor seguindo os estóicos, o acontecimento não é nem possível nem necessário, mas fatal. 
p.37). ${ }^{17}$ Temos portanto uma mesma essência, mas que pode se apresentar em três estados diferentes; assim, o primeiro e o segundo estado são suas encarnações, dizendo respeito às atualizações em conceitos lógicos proposicionais e em estados de coisas designáveis, ao passo que a terceira seria a essência fora destas relações, virtualmente em si mesma. Deleuze assimila este terceiro estado ao sentido, ao expresso. Vejamos como isto se passa no registro da linguagem, das proposições:

O primeiro estado da essência é a essência como significada pela proposição, na ordem do conceito e das implicações de conceito. O segundo estado é a essência enquanto designada pela proposição nas coisas particulares em que se empenha. Mas o terceiro é a essência como sentido, a essência como expressa: sempre nesta secura, animal tantum, esta esterilidade ou esta neutralidade esplêndidas. Indiferente ao universal e ao singular, ao geral e ao particular, ao pessoal e ao coletivo, mas também à afirmação e à negação etc. Em suma: indiferente a todos os opostos. (idem, p.37)

É que, segundo Deleuze, todos estes opostos referem-se exclusivamente à questão em pauta, aos modos da proposição, sempre baseados em relações de significações e conceitos (o primeiro estado) e de designações estritas (o segundo estado). O sentido-acontecimento ultrapassa todo tipo de oposição, já que é neutro (com relação aos modos da proposição) e estéril, impassível (com relação aos estados de coisas) (idem, p.37).

Chegamos então ao último paradoxo, o do absurdo ou dos objetos impossíveis: proposições que designam objetos contraditórios não deixam de ter um sentido. A designação de uma tal proposição não existe, pois o sentido não tem como se efetuar em um estado de coisas. Do mesmo modo, não há significação, que estaria encarregada de estabelecer conceitualmente, formalmente, a possibilidade lógica de alguma efetuação. Mas há sentido. Os exemplos apresentados ("quadrado redondo", "matéria inextensa", "montanha sem vale" (idem, p.38)) mostram bem o que são tais objetos inefetuáveis, mas que não deixam de requerer um sentido extra-existente, extra-proposicional. "Se distinguimos duas espécies de ser, o ser do real como matéria das designações e o ser do possível como forma das significações, devemos ainda acrescentar este extra-ser que define um mínimo comum ao real, ao possível e ao impossível" (idem, p.38). O sentido-acontecimento é pois o terceiro-estado que excede uma física e uma lógica, o real designável

17 Ajudou-nos também, quanto a este ponto, a tese de doutorado de Cláudio Ulpiano, 1998. Por exemplo: no que toca ao mundo pré-medieval de Avicena, "a essência pode ser visada sob três aspectos, nas coisas - individualizada, física; no intelecto - universalizada, lógica; e fora das relações que pode ter com as coisas ou com o intelecto: em si mesma." (pp.104-5) 
e o possível significado. Ele é o transcendental, o impossível que a espécie humana tornou possível...

\section{A estrutura}

No início da sexta série de paradoxos, intitulada Sobre a Colocação em Séries, Deleuze afirma: "O paradoxo de que todos os outros derivam é o da regressão indefinida. Ora, a regressão tem necessariamente a forma serial: cada nome designador tem um sentido que deve ser designado por um outro nome, n1 > n2 >n3 > n4..." (idem, p.39).

O ponto central é que Deleuze vai ler toda seqüência serial não sob o ponto de vista da homogeneidade dos termos que simplesmente se sucedem, mas da heterogeneidade entre os planos que se alternam ao longo da sucessão, e que em suma evidencia uma dupla série, distintas entre si por uma relação basilar, a articulação da diferença entre designação e expressão. Assim:

Desta vez, trata-se de uma síntese do heterogêneo; ou antes, a forma serial se realiza na simultaneidade de duas séries pelo menos. Toda série única, cujos termos homogêneos se distinguem somente pelo tipo ou pelo grau, subsume necessariamente duas séries heterogêneas, cada série constituída por termos do mesmo tipo ou grau, mas que diferem em natureza dos da outra série (eles podem também, como é óbvio, diferir em grau). A forma serial é, pois, essencialmente multisserial. (ibidem)

Toda série é, no mínimo, uma dupla série, indissociável dos paradoxos de que há pouco falávamos. Esta dupla série heterogênea pode ser determinada indistintamente segundo o caminho de dualidades que já verificamos, trilha subsumida no ou pelo sentido: expressões/designações, verbos/nomes, proposições/coisas, acontecimentos em efetuação/misturas corporais. Em realidade, trata-se sempre de uma mesma disposição: enquanto, numa das séries - a que chamaríamos de significante - os termos "trazem em si" o próprio sentido, na outra - a série de significados - temos seus correlatos, as efetuações, as apropriações, os usos. ${ }^{18}$

Da heterogeneidade entre as naturezas dessas duas séries de base, temos que a primeira é sempre excessiva em relação à segunda, ou, pelo inverso, a segunda está em falta relativamente à primeira. Não há paralelismo exato entre elas, qualquer tipo de função biunívoca. Pelo contrário, há um

18 Reproduzimos uma nota de François Wahl (2000, p.131), relevante para o momento: "Teria sido melhor evitar a designação do primeiro como 'significante' e do segundo como 'significado', designação que Deleuze admite poder ocasionar mal-entendidos." 
"desnível essencial", um "desequilíbrio orientado" (idem, p.42) entre as séries, cuja comunicação é garantida pelo estatuto de um terceiro que as articula segundo a diferença entre ambas. Podemos já supor toda a relevância desta via complexa: ela recebe boa parte do acento e da atenção na montagem deleuzeana.

De fato, é justamente esse elemento que impede o fechamento das séries em uma situação de espelho perfeito, de pura semelhança, pela qual um objeto nada mais faria que refletir a imagem do outro, o que terminaria podando qualquer tipo de deslizamento, de escape, de novidade. Este terceiro é portanto o que vai situar a estrutura para além da dialética entre o real e o imaginário, de sua oposição ou complementaridade, relação que até então definia várias chaves teóricas no campo das ciências humanas (Deleuze, 1974, pp.272-3).

De acordo com Deleuze, "a estrutura se encarna nas realidades e nas imagens segundo séries determináveis; mais ainda, ela as constitui encarnando-se, mas não deriva delas, sendo mais profunda que elas, subsolo para todos os solos do real como para todos os céus da imaginação" (idem, p.274). A estrutura, a ordem que será dita simbólica, é portanto o elo que tece as séries, que as entrelaça, uma no plano do real, outra no plano do imaginário, e o faz em heterogeneidade, em diferença, de modo que não há como uma se refletir sobre a outra. O real tende a ser um, a fazer um em sua totalidade aberta; o imaginário é o duplo sempre a se desdobrar deste real, segundo caminhos e variações múltiplas; mas há um terceiro, um "entre", responsável propriamente pelo movimento deste jogo, que o faz girar, que o faz, enfim, acontecer (idem, p.274). Este terceiro, afirma Deleuze, não alude apenas à estrutura, mas também a um certo elemento extraordinário que lhe é propriamente constitutivo, e cujos caracteres deveremos ainda explicitar.

Apresentamos, até agora, na estrutura, a existência de pelo menos duas séries, heterogêneas, deslocadas entre si, e que se comunicam em função de uma certa instância muito particular. Necessitamos agora nos perguntar mais atentamente de que se compõe cada uma destas séries, como precisar seus componentes.

Distintos do real e do imaginário, os elementos simbólicos de uma estrutura "não têm nem designação extrínseca nem significação intrínseca" (idem, p.276), e assim não dizem respeito a lugares cardinais, empíricos, em extensões reais ou imaginárias. No entanto, há um lugar propriamente estrutural, ou, dito melhor, a estrutura está sim num certo lugar. Trata-se de um espaço absolutamente especial, "inextenso, preextensivo, puro spatium constituído cada vez mais como ordem de vizinhança, onde a noção de vizinhança tem precisamente, antes, um sentido ordinal e não uma significação na extensão" (idem, p.276). Eis pois que esta noção de espaço, de posição, é imprescindível à estrutura, que se diz então topológica. Os lugares da 
estrutura são primeiros em relação aos seres e coisas reais que vêm ocupálos, bem como às idéias imaginárias que sempre surgem após ocupados.

Estas unidades de posição se destacam dentro de um puro contínuo na medida em que se determinam reciprocamente, em função de relações diferenciais. Em si, não têm valor, não têm existência, nada designam, nada significam - podemos referi-las, determiná-las, apenas a partir daquilo que as diferencia entre si.

Um bom caso vem da fonologia. Os fonemas - desde que não referem partículas sonoras reais nem possíveis significações imaginárias - destacam-se do contínuo sonoro de que fazem parte devido às relações diferenciais que se estabelecem no interior de uma língua, que se manifestam em seus falantes, e que prescrevem, por exemplo, a distância mútua entre um 'b' e um 'p'. ${ }^{19}$ Em si mesmo, um 'b' ou um 'p' nada dizem, porém, na medida em que se trata de um 'b' e não de um 'p' (ou vice-versa), eles podem emergir simbolicamente e ocupar lugares singulares dentro da paisagem ordinal fonemática de uma dada língua. No limite, cada fonema é aquilo que todos os outros não são, e de maneira que fica assim indicado o que cada um deve ser, tudo se tratando, em suma, de relações diferenciais e de lugares correspondentes. "É este processo de uma determinação recíproca no interior da relação que nos permite definir a natureza simbólica" (idem, p.280). Estes lugares diferenciais, estas unidades de posição que compõem as séries são portanto singularidades, pontos especiais que se destacam dentro de um puro spatium, de um continuum, sempre distribuindo sua ressonância, seus efeitos sobre as proximidades, a circunvizinhança. Diremos ainda: as singularidades da estrutura são acontecimentos. ${ }^{20}$

Sabemos que os fonemas são a menor unidade lingüística capaz de estabelecer a distinção entre dois termos diferentes ('bote', e não 'pote'). Os fonemas, em sua singularidade, são a própria diferença, o nível fonológico básico. As singularidades fonemáticas, a partir mesmo das relações e das regras diferenciais pelas quais determinam-se reciprocamente, se conjugam e se combinam, gerando os sons, as letras, as sílabas típicas de uma língua. Nível a nível, área por área, poderíamos falar de alguns dos objetos de pesquisa então estudados: fonemas, morfemas, semantemas, parentemas, mitemas, literemas... De qualquer modo, "toda estrutura apresenta os dois aspectos seguintes: um sistema de relações diferenciais segundo os quais os elementos simbólicos se determinam reciprocamente, um sistema

19 Cf. referências sobre a fonologia em Deleuze, 1974, p.279

20 Deleuze, 1998, p.53: "Eis porque é inexato opor a estrutura e o acontecimento: a estrutura comporta um registro de acontecimentos ideais, isto é, toda uma história que lhe é interior". 
de singularidades que corresponde a essas relações e traça o espaço da estrutura" (idem, p.280).

Ou bem inventariamos as manifestações empíricas de um domínio, aí buscando encontrar as chamadas homologias estruturais, isto é, o conjunto de lugares singulares que insiste e se revela em cada série estudada segundo os possíveis acentos diferenciais, ou, pelo inverso, partimos já das singularidades, atentamos para as relações diferenciais em função das quais se discriminam, e chegamos aos elementos simbólicos últimos. O importante é - dentro das variações e deslocamentos característicos das séries firmar o confronto entre sistemas de diferenças, entre séries de relações e de lugares que tenham chance de preservar algum tipo de homologia. Consideremos finalmente que "os elementos simbólicos encarnam-se nos seres e objetos reais do domínio considerado; as relações diferenciais atualizamse nas relações reais entre esses seres; as singularidades são outros tantos lugares na estrutura, que distribuem os papéis ou atitudes imaginários dos seres que vêm ocupá-los" (idem, p.281).

Disto tudo, ratificamos desde já uma importante consideração relativa ao nosso problema principal, e que constituirá o fundo mesmo do próximo capítulo. Se, quanto a estas singularidades, não cabe designação extrínseca ou significação intrínseca, o sentido é o que justamente emerge - ele é um efeito - da combinação simbólica e diferencial de lugares que, em si, não detém qualquer sentido. "Há profundamente um não-sentido do sentido, de onde resulta o próprio sentido (...) [e] que o faz valer e o produz circulando na estrutura" (idem, p.278). O não-sentido é portanto a própria condição do sentido, seu alicerce paradoxal, e que o configura segundo possibilidades combinatórias sempre múltiplas e desmedidas, pelo que o sentido, aliás, é necessariamente excessivo.

Eis que se nos apresenta, novamente, a caprichosa ponte que se firma entre não-sentido e sentido, ou, por outra, o terceiro enigmático que assegura a heterogeneidade entre duas séries básicas de trabalho, uma sempre desencontrada da outra. Este "ponto de desencontro", móvel, é, sabemos, quem especificamente assevera a comunicação entre as séries, impedindo que uma se dobre imaginariamente sobre a outra. Deleuze chama este lugar nodal de casa vazia.

Trata-se de um lugar bastante específico, sem qualquer registro de si, dessemelhante a si, caracteristicamente vinculado à figura do paradoxo. Anima simultaneamente as duas séries: numa, é lugar sem ocupante, ali onde ele não está quando o procuramos; noutra, é ocupante sem lugar, precisamente quando não o encontramos onde ele está (Deleuze, 1998, p.43). Seria o próprio espelho, preciso em sua potência de refração, e de modo que suas faces nunca se complementam, nunca se encaixam. Eis porque Deleuze gosta de comparar o sentido a um efeito ótico. (idem, p.8 e p.73; 1974, 
p.278). Este objeto falta em seu lugar (1998, p.43), uma ausência presente, mas é em função dele que tudo passa, que tudo se passa - não se fica imune a ele, não se é mais o mesmo....

É propriamente a casa do não-sentido, mas que, ao percorrer as séries do mundo, gera sentido pelos seus arredores, distribui seus efeitos, faz acontecer. Diríamos: é o lugar do mistério! "Como denominá-lo, senão Objeto = x, Objeto da adivinhação ou grande Móvel?" (Deleuze, 1974, pp.2912). Eis aí a instância simbólica por excelência, ponto cego que dá a ver, grau zero que pede passagem. Vagueando incessantemente, esta anomalia faz toda a diferença, e ela é o (não-)lugar sempre muito fluido que faz escorrer o simbólico desde sua raia mais básica. Ao que parece, assim vamos dando sentido às coisas - sentido como construção, como invenção -, na medida mesma em que o mundo circula e nos envolve em sua voragem sem fim.

Podemos então tentar sumarizar, com Deleuze, as condições mínimas de uma estrutura em geral:

1. São necessárias, pelo menos, duas séries heterogêneas, das quais uma será determinada como "significante" e a outra como "significada" (...); 2. Cada uma destas séries é constituída por termos que não existem a não ser pelas relações que mantêm uns com os outros. A estas relações, ou antes, aos valores destas relações, correspondem acontecimentos muito particulares, isto é, singularidades designáveis na estrutura (...); 3. As duas séries heterogêneas convergem para um elemento paradoxal, que é como o seu "diferenciante". Ele é o princípio de emissão das singularidades. Este elemento não pertence a nenhuma série, ou antes, pertence a ambas ao mesmo tempo e não pára de circular através delas. (1998, p.53)

\section{Considerações finais}

Retomaremos, neste tópico, os vínculos das noções apresentadas com as Idéias propostas por Deleuze. Parece-nos relevante apontar: sentido, acontecimento, estrutura e Idéia têm o mesmo estatuto. ${ }^{21}$ Trata-se sempre de valorizar e de precisar cada vez mais uma dimensão ideal, mas real, e que se dá como efeito, que é produzida ao mesmo tempo em que recolhemos suas efetuações, consoante o que vimos no capítulo anterior. Tentaremos esclarecer um pouco mais esse contexto, agora enfatizando os elementos estruturais - estrutura que, em nosso caso, é a do sentido - como componentes da Idéia. Ao mesmo tempo, esperamos enxergar melhor um outro fator extremamente relevante em toda esta conceituação: o movimento incessante posto em jogo. Para tudo isto, vamos nos valer de um par conceitual bastante potente, e essencial a Deleuze. Trata-se do par virtual-atual.

21 Como, aliás, confirma Machado (1990, p.155) 
Comecemos pela seguinte proposição: “(...). não há qualquer dificuldade em conciliar este duplo aspecto pelo qual a Idéia é constituída de elementos estruturais que não têm sentido por si mesmos, mas constitui o sentido de tudo o que ela produz (estrutura e gênese)" (Deleuze, 1988, p.254). Efetivamente, a Idéia é bem estabelecida: temos pelo menos duas séries uma das quais será dita significante, a outra, significada - de pontos singulares, que se firmam e se comunicam sempre em divergência, em diferença, mediante a casa vazia. Entre as duas séries, o que se passa é precisamente o processo do sentido. Se o sentido tem uma dimensão empírica, correspondente aos estados de coisas em suas significações de linguagem, ele tem também, como postulamos nas primeiras páginas deste capítulo, uma dimensão transcendental, que podemos aproximar às séries significantes. Para introduzir o virtual e o atual, usaremos um trecho de Em que se pode reconhecer o estruturalismo?, no qual Deleuze afirma, retomando Proust:

Da estrutura, diremos: real sem ser atual, ideal sem ser abstrata (...). Extrair a estrutura de um domínio é determinar toda uma virtualidade de coexistência que preexiste aos seres, aos objetos e às obras desse domínio. Toda estrutura é uma multiplicidade de coexistência virtual. (1974, p.283) ${ }^{22}$

De uma só vez, o autor indica a estrutura como ideal, real e composta por virtuais. O que são estes virtuais? Anteciparemos o seguinte cotejo, que ficará paulatinamente mais claro ao longo das páginas que ainda virão: o virtual expõe o transcendental, o intensivo, campo especulativo pré-subjetivo e pré-objetivo composto por uma multiplicidade de instâncias ainda informais (as diferenças, as singularidades), dimensão inconsciente, pré-lingüística, problemática, pré-sensível, ligada a uma experiência real. O atual relata o empírico, o extenso, campo dos sujeitos e objetos já formados, a dimensão própria da consciência, da linguagem, das soluções, do vivido e das experiências possíveis comuns. "Todo objeto é duplo, sem que suas duas metades se assemelhem, sendo uma a imagem virtual e, a outra, a imagem atual. Metades desiguais ímpares" (Deleuze, 1988, p.337). ${ }^{23}$

Especificamente no artigo referido, Deleuze firma a complexidade de um duplo movimento - que vai expor precisamente as duas séries da estrutura -, de acordo, numa ponta, com um processo de virtualização ou dife-

22 Grifo do autor. Quanto à utilização da fórmula de Proust, cf. também Deleuze, 1987, p.61.

23 No que toca ao par virtual-atual, parece-nos que as principais referências são Em que se pode reconhecer o estruturalismo? e Diferença e repetição. Neste, Deleuze define detidamente as duas faces da realidade mencionadas: elas equivalem aos capítulos IV, Síntese ideal da diferença, e V, Síntese assimétrica do sensível, e respondem, nesse livro, pelo processo mais completo de caracterização da ontologia de nosso autor, que aliás visitaremos no último capítulo deste trabalho. 
rençação, na outra, segundo um processo de atualização, de diferenciação. (Deleuze, 1974, p.283-5). De fato, há uma reversibilidade e uma coexistência permanente entre estes processos, o virtual que continuamente se atualiza, o atual que mergulha no seu virtual; por direito, há uma direção da gênese que parte do virtual e vai ao atual.

Comentávamos no início deste trecho da dissertação que a sutileza maior é, quanto ao trabalho e ao trajeto do pensamento, partindo do empírico, atingir a dimensão transcendental precedente, bem como daí perseguir o retorno rumo ao estado de coisas. Aquém portanto das efetuações sensíveis, das séries atuais, necessitaríamos encontrar a estrutura de relações diferenciais e pontos singulares que exibe as séries de ordem virtual.

O âmbito virtual da estrutura é excessivo, inesgotável, e de modo que continuamente, segundo caminhos e condições sempre ocasionais e exclusivas, ela atualiza, em divergência, algum conjunto de relações e de singularidades. (idem, p.284). Temos assim, em suma, o duplo aspecto determinável da estrutura, do sentido, do acontecimento ou da Idéia, suas metades: a diferençação e a diferenciação. ${ }^{24}$ São metades dessemelhantes e de naturezas distintas, mas ambas reais, que se espelham desigualmente dado um vazio sempre movente.

A diferençação é a multiplicidade das relações diferenciais e dos pontos singulares correspondentes, dentro de um domínio considerado. Tratase de elementos, sem designação nem significação, mas que se apontam e se precisam reciprocamente a partir de relações diferenciais.

Já a diferenciação converte tais relações diferenciais em espécies qualitativamente distintas e as singularidades nas partes e figuras extensas relativas a cada espécie. A diferenciação é especificação e organização, é qualificação e composição, é qualitativa e quantitativa. Ela desdobra as virtualidades em seus produtos empíricos, mas sem jamais esgotá-las, mesmo porque elas perduram segundo as linhas divergentes atuais (idem, p.284; 1988, pp.337-8 e 353-4).

Podemos então atentar: a metade virtual da estrutura nos diz que ela é diferencial em si, diferençada quanto aos seus termos e relações; de outro lado, ela é o que se diferencia no espaço e no tempo, ela é diferenciadora quanto aos seus efeitos - mas sem jamais se perder, reserva sempre plena, inexaurível. (Deleuze, 1974, p.285-6). Eis então a estrutura: diferençação dos termos e relações, diferenciação dos efeitos.

24 Cf. também Machado (1990, p.157). Ou ainda Orlandi (2000, p.55): "Em sua inteireza, a Idéia é um sistema de diferenças determinado por uma complexa articulação de "diferençações" (différentiations) e "diferenciações" (différenciations). Toda e qualquer coisa, seja natural ou artificial, seja física ou social, seja uma cor ou um poema, até mesmo um conceito, comporta, no mínimo, essa dupla articulação própria da Idéia dita 'inteira'". 
Ratifiquemos, finalmente, o que desencadeia o andamento dos dois processos, o que comunica um ao outro: um terceiro especial, o diferenciador de diferenças, casa vazia. Este é, propriamente, o catalisador de movimentos, uma vez que ele faz tudo acontecer e ressoar, é ele que "determina ou desencadeia, que diferencia a diferenciação do atual em sua correspondência com a diferençação da Idéia" (Deleuze, 1988, p.354). ${ }^{25}$ Se uma face nada tem a ver com a outra (pois são desiguais). é porque uma se reverte na outra, não se dá sem a outra, mas sempre ali pelo meio, onde um notável portal garante o mundo em sua discordância comunicante, marcha da criação e da novidade.

Chegamos no nível da estrutura, das determinações transcendentais, virtuais, relativas ao sentido: Idéia. Com este percurso algo ziguezagueante, particularmente entre a Lógica do sentido e Em que se pode reconhecer o estruturalismo?, apresentamos e até mesmo antecipamos alguns dos principais elementos envolvidos na tessitura proposta pelo autor. Nas séries seguintes, Deleuze retomará e fará variar estas figuras, estabelecerá novas relações, tudo a fim de examinar ainda mais demoradamente as maquinarias conceituais produtoras de sentido. Ele continuará a refinar sua montagem.

SALES, A. C. Deleuze and The logic of sense: structure as a problem. Trans/Form/ Ação, (São Paulo), v.29(2), 2006, p.219-239.

- ABSTRACT: This article intends to follow the main movements presented by the philosopher Gilles Deleuze (1925-1995). to propose a strucuture of the sense according to The logic of sense (1969). In order to do this, trying to achieve the very particular Deleuzian structuralism, we will follow especially some arguments established between the fourth (Of dualities). and the eighth (Of structure). series of this book, as well as points of the text How do we recognize structuralism? (1974).

- KEYWORDS: Deleuze; logic of sense; structure; paradoxe; Carroll.

\section{Referências bibliográficas}

BADIOU, Alan. Da vida como nomes do ser. In: ALLIEZ, Éric (org). Gilles Deleuze: uma vida filosófica. São Paulo: Ed.34, 2000.

25 Relativamente aos capítulos IV e V, que estabelecem a ontologia, Deleuze costuma chamar de Idéia dialética ou apenas de Idéia a metade virtual do sistema em jogo, as diferençações que aí ocorrem. Há pouco víamos, com Orlandi, que a Idéia dita inteira diz respeito ao conjunto formado pelas virtualizações e atualizações: a mesma p.354 de Diferença e repetição (1988) apresenta uma tal proposição ("A Idéia inteira é tomada no sistema matemático-biológico da diferençação/diferenciação"). 
BADIOU, Alan. Deleuze: o clamor do ser. Rio de Janeiro: Jorge Zahar, 1997.

CARROLL, Lewis. Alice: edição comentada. Rio de Janeiro: Jorge Zahar, 2002. Aventuras de Alice. São Paulo: Summus, 1980.

CHAUI, Marilena. Introdução à filosofia: dos Pré-Socráticos a Aristóteles. Vol. I. São Paulo: Companhia das Letras, 2002.

COPI, Irving. Introdução à lógica. São Paulo: Mestre Jou, 1978.

DELEUZE, Gilles. (1968). Diferença e repetição. Rio de Janeiro: Ed. Graal, 1988. (1972). Em que se pode reconhecer o Estruturalismo? In CHÂTELET François (org). História da filosofia - idéias, doutrinas. Vol 8. Rio de Janeiro: Zahar, 1974

(1969). Lógica do sentido. São Paulo: Perspectiva, 1998

(1964). Proust e os signos. Rio de Janeiro: Forense-Universitária, 1988.

DIAS, Sousa. Lógica do Acontecimento - Deleuze e a Filosofia. Porto: Afrontamento, 1995.

LALANDE, André. Vocabulário técnico e crítico da filosofia. 3 ed. São Paulo: Martins Fontes, 1999

MACHADO, Roberto. Deleuze e a filosofia. Rio de Janeiro: Graal, 1990.

ORLANDI, Luiz. Linhas de ação da diferença. In: ALLIEZ, Éric (org). Gilles Deleuze: Uma Vida Filosófica. São Paulo: Ed.34, 2000.

PELBART, Peter. O tempo não-reconciliado. São Paulo: Perspectiva: Fapesp, 1998.

ULPIANO, Cláudio. O pensamento de Deleuze ou a grande aventura do espírito. Tese (Doutorado). Campinas: Programa de Pós-Graduação em Filosofia da Universidade Estadual de Campinas, 1998.

WAHL, François. O copo de dados do sentido. In: ALLIEZ, Éric (org). Gilles Deleuze: uma vida filosófica. São Paulo: Ed.34, 2000. 